\title{
Query fever: an opportunity to understand the disease better
}

D Coulombier (denis.coulombier@ecdc.europa.eu)

1. European Centre for Disease Prevention and Control, Stockholm, Sweden

Citation style for this article:

Citation style for this article: Coulombier D. Query fever: an opportunity to understand the disease better. Euro Surveill. 2010;15(12):pii=19526. Available online: http://www.eurosurveillance.org/ViewArticle.aspx?Articleld $=19526$

This week's issue of Eurosurveillance presents two articles on $Q$ fever. A surveillance report about a $Q$ fever outbreak in Cheltenham, United Kingdom (UK), describes the traditional pattern of $Q$ fever epidemiology involving clusters of cases reported around farms with infected animals (sheep, goats) [1]. The second article provides an update on a long-lasting and ongoing $Q$ fever outbreak with a considerable increase in cases observed over the past three years, indicating an entrenchment of $Q$ fever in certain areas of the country [2].

Q fever is a mandatorily notifiable disease in the European Union (EU). Until recently, a few hundred cases were reported annually, often in the context of circumscribed outbreaks [3]. The great majority of reported cases in the EU were adults with a male to female ratio of 1.8 and a seasonal pattern with more cases reported during summer months. However, given its non-specific clinical picture and mild course in the majority of cases, $Q$ fever is known to be under-diagnosed and therefore under-reported [3]. Seroepidemiological studies conducted in some regions of EU Member States have indicated a seroprevalence ranging from $1 \%$ to $60 \%$ [4-7].

Intensive animal husbandry has long been associated with large epizootics. Europe still sees large outbreaks of e.g. swine fever and outbreaks recently occurred in Spain, Germany and Luxembourg and were seen in the UK in 2000 and in the Netherlands in 1997 [8]. The Netherlands also saw a 2003 influenza $A\left(\mathrm{H}_{7} \mathrm{~N}_{7}\right)$ virus outbreak in poultry. All the above outbreaks led to the culling of a large number of animals and the influenza $A\left(\mathrm{H}_{7} \mathrm{~N}_{7}\right)$ outbreak affected several hundreds of humans [9]. Intensive animal husbandry is now associated with the emergence of a large $Q$ fever epidemic, affecting human health significantly and raising questions about the intensive animal husbandry in the proximity of densely populated areas as is the case in the Netherlands. It seems unlikely that the disease will spread geographically to areas with less intensive animal husbandry and at the pace noted in the Netherlands. However, it cannot be excluded that spores may spread through wind, as described in the article by Wallensten et al. (UK), and cases could also occur beyond the Netherlands, when farms with infected animals are located closely to borders.

Van der Hoek et al. (NL) report that around $20 \%$ of the Q fever cases reported in the Netherlands were admitted to hospital in 2008 and 2009. An earlier publication by Raoult et al. describes that 2 to $5 \%$ of cases were hospitalised in past outbreak settings [10]. Wallensten et al. are using these reference hospital admission percentages to estimate that possibly 500 people may have been infected in the Cheltenham outbreak. Applying the same range of hospital admission percentages to the outbreak in the Netherlands would result in 10,000 to 20,000 cases having occurred there in 2009 .

Coxiella burnetii DNA was detected in some products for blood donation from affected areas in the Netherlands, and the subsequent precautionary screening of blood in areas with a high incidence of $Q$ fever raises the question whether blood donors returning from affected areas and giving blood while potentially experiencing asymptomatic bacteraemia should potentially defer from doing so. In their paper, van der Hoek et al. express concerns that in the first few weeks of 2010 an important increase in cases was noted, earlier than compared with previous years. They conclude that $\mathrm{Q}$ fever is expected to remain a significant problem over the coming years while it is hoped that the number of human cases in 2010 will stabilise. Therefore, this rapid communication is very timely in alerting about the foreseeable persistence of the $\mathrm{Q}$ fever epidemic in the Netherlands in 2010. This epidemic brings a unique opportunity to learn more about a disease for which many questions still remain. It stresses again the need to complete and communicate preliminary results of ongoing studies in similar outbreak situations which are necessary for the rapid implementation of public health measures regarding risk groups, chronic disease, pregnant women and blood donation. 


\section{References}

1. Wallensten A, Moore P, Webster H, Johnson C, van der Burgt G, Pritchard G, et al. Q fever outbreak in Cheltenham, United Kingdom, in 2007 and the use of dispersion modelling to investigate the possibility of airborne spread . Euro Surveill. 2010;15(12). pii=19521. Available from: http://www. eurosurveillance.org/ViewArticle.aspx?Articleld=19521

2. Hoek W, Dijkstra F, Schimmer B, Schneeberger PM, Vellema P, Wijkmans C, et al. Q fever in the Netherlands: an update on the epidemiology and control measures. Euro Surveill. 2010;15(12) pii=19520. Available from: http://www.eurosurveillance.org/ ViewArticle.aspx?Articleld $=19520$

3. European Centre for Disease Prevention and Control (ECDC). Annual epidemiological report on communicable diseases in Europe 2009. Revised edition. Stockholm, European Centre for Disease prevention and Control. Available from: http:// www.ecdc.europa.eu/en/publications/Publications/o910 SUR_Annual_Epidemiological_Report_on_Communicable_Diseases_in_Europe.pdf

4. Bartolomé J, Riquelme E, Hernandez-Péréz N, Garcia-Ruiz S, Luján R, Lorente S, et al. [Seroepidemiology of Coxiella burnetii infection among blood donors in Albacete]. Enferm Infecc Microbiol Clin. 2007;25(6):382-6. [Spanish]

5. Brandt D, Putzker M, Thode C, Thoele A. Main examination rules for German army blood donors including occurrence of epidemic infectious diseases with consequences for the use of blood products. Clinical Laboratory. 1998;44(12):997-1001.

6. Literak I. Prevalence of antibodies to Coxiella burnetii in blood donors in the Czech Republic. Cent Eur J Public Health. 1994;2(1):52-4.

7. Nebreda T, Contreras E, Jesús Merino F, Dodero E, Campos A. Outbreak of $Q$ fever and seroprevalence in a rural population from Soria Province. Enferm Infecc Microbiol Clin. 2001;19(2):57-60.

8. European Commission. [Internet]. EU-AgriNet. Fighting swine fever in Europe. Available from: http://ec.europa.eu/research/ agriculture/projects_showcaseo9_en.htm9

9. National institute for Public Health and the Environment (RIVM). Bosman A, Mulder YM, Leeuw JRJ de, Meijer A, Du Ry van Beest Holle M, Kamst RA, et al. Avian Flu Epidemic 2003: Public health consequences. Available from: http://www.rivm. $\mathrm{nl} /$ bibliotheek/rapporten/630940004.html

10. Raoult D, Marrie TJ, Mege JL. Natural history and pathophysiology of Q fever. Lancet Infect Dis. 2005;5(4):219-26 